\title{
Peran kompetensi melalui berfikir komputasi dalam membangun karir di dunia IT menuju Era Society 5.0
}

\author{
${ }^{1}$ Bita Parga Zen, ${ }^{2}$ Gita Fadila Fitriana, ${ }^{3}$ M. Azrino Gustalika \\ ${ }^{1}$ Program Studi Teknik Informatika, Fakultas Informatika, Institut Teknologi Telkom Purwokerto \\ ${ }^{2}$ Program Studi Rekayasa Perangkat Lunak, Fakultas Informatika, Institut Teknologi Telkom \\ Purwokerto \\ ${ }^{3}$ Program Studi Teknik Informatika, Fakultas Informatika, Institut Teknologi Telkom Purwokerto \\ 1bita@ittelkom-pwt.ac.id, ${ }^{2}$ gita@ittelkom-pwt.ac.id, ${ }^{3}$ azrino@ ittelkom-pwt.ac.id
}

\begin{abstract}
Abstrak: Society 5.0 merupakan suatu konsep Society yang berpusat pada manusia (human-centered) dan berbasis teknologi (technology based) yang pertama kali dikembangkan di Jepang. pengembangan dari revolusi industri 4.0 yang dinilai berpotensi mendegradasi peran manusia dengan mengembangkan kecerdasan buatan, penjelasan mengenai Science performance (PISA) diharapkan semua peserta memahami terkait literasi ilmiah seorang anak berusia 15 tahun di Indonesia dalam penggunaan pengetahuan ilmiah untuk mengidentifikasi pertanyaan, memperoleh pengetahuan baru, menjelaskan fenomena ilmiah, dan menarik kesimpulan berbasis bukti tentang masalah yang terkait dengan sains, sebagai masyarakat baru yang menggabungkan teknologi baru ini di semua industri dan aktivitas sosial dan mencapai pembangunan ekonomi dan solusi untuk masalah sosial secara paralel. Hal ini menjadi sebuah perhatian bagi kita semua bahwa pentingnya sebuah literasi, untuk memulai literasi dibutuhkan sebuah pemikiran Berfikir Komputasi, oleh karena itu dalam pengabdian masyarakat ini dibutuhkan pentingnya sebuah pemikiran dalam berfikir kompetensi agar dapat bersaing di dunia industri teknologi maupun menuju era society 5.0 agar kedepan indonesia menjadi negara maju dan sumber daya manusia dapat bersaing di dunia internasional.
\end{abstract}

Kata Kunci: Society 5.0, Berfikir Komputasi, PISA, Revolusi Industri

\section{Pendahuluan}

Di era digital saat ini kemajuan perekonomian, sosial, budaya maupun teknologi tidak lepas dari adanya peran manusia untuk mengubah segala bentuk alih fungsi teknologi, kita ketahui bahwa saat ini kita telah melalui beberapa perubahan antara lain, Society 1.0 yang dikenal dengan Hunter gatherer Society adalah masyarakat yang metode bertahan hidup utamanya ialah memburu atau mengumpulkan secara langsung binatang dan tumbuh-tumbuhan liar yang dapat dimakan, Society 2.0 yang dikenal dengan Agrarian Society adalah masyarakat yang melakukan kegiatan dengan bertani, pemeliharaan tanaman dan memanfaatkan lahan pertanian, Society 3.0 yang dikenal dengan Industrial Society Manusia yang tadinya bercocok tanam dan beternak hewan diganti dengan bekerja di pabrik-pabrik dengan sistem upah. Kapitalisme menjadi akar dari kemajuan zaman, kemajuan teknologi dan kemajuan ekonomi sekaligus menjadi faktor besar kesenjangan masyarakat dan kerusakan lingkungan. Society 4.0 yang dikenal dengan Industrial Society melalui penggunaan Teknologi Informasi dengan cara kreatif dan produktif, Dalam masyarakat informasi, sumber daya yang diolah adalah Informasi, yang terakhir adalah Society 5.0 merupakan suatu konsep Society yang berpusat pada manusia (humancentered) dan berbasis teknologi (technology based) yang pertama kali dikembangkan di Jepang. pengembangan dari revolusi industri 4.0 yang dinilai berpotensi mendegradasi peran manusia dengan 
mengembangkan kecerdasan buatan atau artificial intelligence akan mentransformasi Big Data yang dikumpulkan melalui internet pada segala bidang kehidupan. Internet of Things menjadi suatu kearifan baru, yang akan didedikasikan untuk meningkatkan kemampuan manusia membuka peluang-peluang bagi kemanusiaan (Government.C. O. 2018).

Dalam masyarakat informasi masa lalu, praktik umum adalah mengumpulkan informasi melalui jaringan dan menganalisisnya oleh manusia. Di Society 5.0, bagaimanapun, orang, benda, dan sistem semuanya terhubung di dunia maya dan hasil optimal yang diperoleh oleh AI melebihi kemampuan manusia yang diumpankan kembali ke ruang fisik. Proses ini membawa nilai baru bagi industri dan masyarakat dengan cara yang sebelumnya tidak mungkin dilakukan. mengemudi otomatis, teknologi AI menjadi seseorang seperti manusia, produksi pabrik otomatis yang dilakukan oleh sebuah robot Melalui sensor yang terhubung dengan analisis dari pemanfaatan AI dan Big Data. Dalam menghadapi perubahan besar di dunia, teknologi baru seperti IoT, robotika, AI, dan Big Data, yang semuanya dapat memengaruhi jalannya masyarakat, terus berkembang. Jepang berupaya mewujudkan Society 5.0 sebagai masyarakat baru yang menggabungkan teknologi baru ini di semua industri dan aktivitas sosial dan mencapai pembangunan ekonomi dan solusi untuk masalah sosial secara paralel (Serpa, S \& Ferreira, 2018).

Menurut situs Science performance (PISA) 2018 yang merupakan Worldwide Ranking - average score of math, science and reading mengukur literasi ilmiah seorang anak berusia 15 tahun dalam penggunaan pengetahuan ilmiah untuk mengidentifikasi pertanyaan, memperoleh pengetahuan baru, menjelaskan fenomena ilmiah, dan menarik kesimpulan berbasis bukti tentang masalah yang terkait dengan sains. Skor rata-rata adalah ukuran. (OECD, 2021) yang menjadi perhatian kita bersama adalah Indonesia cukup jauh tertinggal dibanding negara di asia seperti Australia, Korea dan Jepang. Hal ini menjadi sebuah perhatian bagi kita semua bahwa pentingnya sebuah literasi, untuk memulai literasi dibutuhkan sebuah pemikiran Berfikir Komputasi, karena dalam Berfikir komputasi merupakan proses berpikir yang terlibat dalam solusi mereka sehingga solusi direpresentasikan dalam bentuk yang dapat dilakukan secara efektif dilakukan untuk memperoleh dalam pemroses sebuah informasi (Valerie J.Shute., ChenSun \& Jodi Asbell Clarke. 2017) oleh karena itu dalam pengabdian masyarakat ini dibutuhkan pentingnya sebuah pemikiran dalam berfikir kompetensi agar dapat bersaing di dunia industri maupun menuju society 5.0 agar kedepan indonesia menjadi negara maju dan harapan nya sumber daya manusia dapat bersaing di dunia.

\section{Realisasi Kegiatan}

Tempat dan Waktu. Kegiatan pengabdian masyarakat dilakukan secara virtual melalui zoom meeting pada hari Jumat tanggal 12 Maret 2021 pukul 09.00 WIB sampai pukul 11.30

Khalayak Sasaran. Yang menjadi khalayak pada pengabdian masyarakat ini adalah Masyarakat umum, Pelajar dan Mahasiswa

Metode Pengabdian. Metode yang disampaikan yaitu dengan berkolaborasi bersama mitra dari PT Enigmacamp dan Institut Teknologi Telkom Purwokerto mengenai peluang karir di dunia IT menuju revolusi society 5.0 adapun tahapan nya yaitu :

1. Memberikan materi penyampaian mengenai society 5.0 kedepan yang akan dihadapi oleh negara maju dan bagaimana indonesia dalam mempersiapkan reslousi society 5.0

2. Memberikan penjelasan mengenai pentingnya sebuah kompetisi dalam Berfikir Kompetensi dimana pada tahapan nya yaitu dijelaskan mengenai Berfikir algoritma dengan cara untuk mencapai solusi melalui definisi yang jelas tentang langkah-langkah yang diperlukan, berfikir Kooperatif, berfikir Kreatif, Berfikir kritis. dan baagaimana menghadapi problem solving 
3. Memberikan waktu untuk sharing session dan tanya jawab kepada para peserta webinar

Indikator Keberhasilan. Keberhasilan program webinar pengabdian masyarakat mengenai kompetensi berfikir komputasi menuju era societ 5.0 dinilai berdasarkan seberapa besar penyerapan tenaga kerja saat ini dan kebutuhan teknologi informasi saat ini terhadap lulusan dari institut teknologi telkom yang diserap oleh industri. Hal ini berdasarkan data dari institusi. Adanya webinar ini memberikan gambaran akan persaingan dunia kerja kedepan melalui pentingnya berfikir algoritma yang baik, berfikir kooperatif, berfikir kreatif, berfikir kritis dan penyelesaian masalah.

Metode Evaluasi. Metode evaluasi yang dilakukan pada webinar ini yaitu yang pertama adalah dengan cara memberikan materi mengenai New Society 5.0 dengan memberikan gambaran mengenai revolusi industri mulai dari revolusi 1.0, 2.0, 3.0, 4.0 dan 5.0 ke dalam cakupan teknologi dari masa ke masa sampai semua peserta memahami revolusi ini.
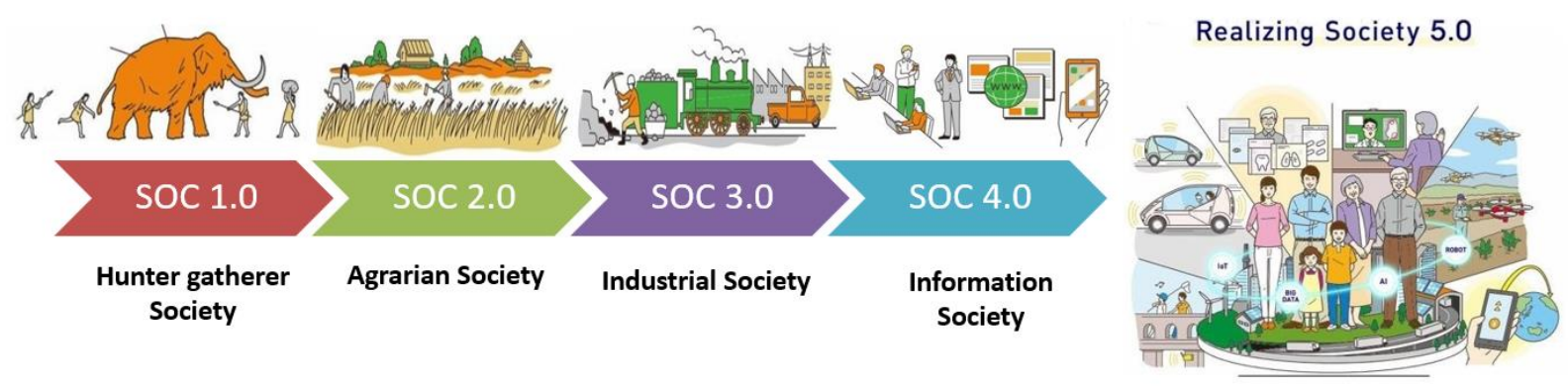

Gambar 1. Tahapan menuju Realizing Society 5.0

Selanjutnya melakukan tahapan penjelasan mengenai Science performance (PISA) diharapkan semua peserta memahami terkait literasi ilmiah seorang anak berusia 15 tahun di Indonesia dalam penggunaan pengetahuan ilmiah untuk mengidentifikasi pertanyaan, memperoleh pengetahuan baru, menjelaskan fenomena ilmiah, dan menarik kesimpulan berbasis bukti tentang masalah yang terkait dengan sains.

\section{Hasil}

Pada materi ini disampaikan dengan topik "Computational Thinking Competencies". Ia menjelaskan mengenai computational thinking competencies yang terdiri dari Alghoritmic Thinking, Cooperativity, Creativity, Critical Thinking, dan Problem Solving. Pada webinar ini juga mengungkapkan jika pada berpikir komputasi atau computational thinking dapat memberikan solusi dari sebuah masalah yang sistematis. Solusi tersebut dipresentasikan dalam bentuk yang lebih efektif untuk memberikan sebuah informasi selanjutnya dengan Berpikir komputasi tidak hanya dapat dikenalkan dan dikembangkan oleh pelajaran komputer atau pemrograman, tetapi dapat diterapkan dalam berbagai disiplin ilmu, disamping itu seseorang dapat Percaya diri dalam berhadapan dengan kompleksitas masalah yang lebih besar dan lebih sulit sehingga seorang bisa belajar lebih efisien dan optimal dalam menyelesaikan persoalan-persoalan dalam semua pekerjaan, karena terbiasa mencari solusi optimal, dan membentuk pola solusi yang akan mempercepat dalam melakukan problem solving.

Materi yang dilakukan pada webinar ini yaitu yang pertama adalah dengan cara memberikan materi mengenai New Society 5.0 dengan memberikan gambaran mengenai revolusi industri mulai dari 1.0, 2.0, 3.0, 4.0 dan 5.0 ke dalam cakupan teknologi dari masa ke masa sampai semua peserta memahami apa itu sociey dan bagaimana penerapan nya dalam dunia industri saat ini. Metode yang disampaikan yaitu dengan berkolaborasi bersama mitra dari PT Enigmacamp dan Institut Teknologi Telkom Purwokerto mengenai peluang karir di dunia IT menuju revolusi society 5.0 adapun tahapan nya yaitu: 
1. Memberikan materi penyampaian mengenai society 5.0 kedepan yang akan dihadapi oleh negara maju dan bagaimana indonesia dalam mempersiapkan reslousi society 5.0

2. Memberikan penjelasan mengenai pentingnya sebuah kompetisi dalam Berfikir Kompetensi dimana pada tahapan nya yaitu dijelaskan mengenai Berfikir algoritma dengan cara untuk mencapai solusi melalui definisi yang jelas tentang langkah-langkah yang diperlukan, berfikir Kooperatif, berfikir Kreatif, Berfikir kritis. dan baagaimana menghadapi problem solving

3. Memberikan waktu untuk sharing session dan tanya jawab kepada para peserta webinar

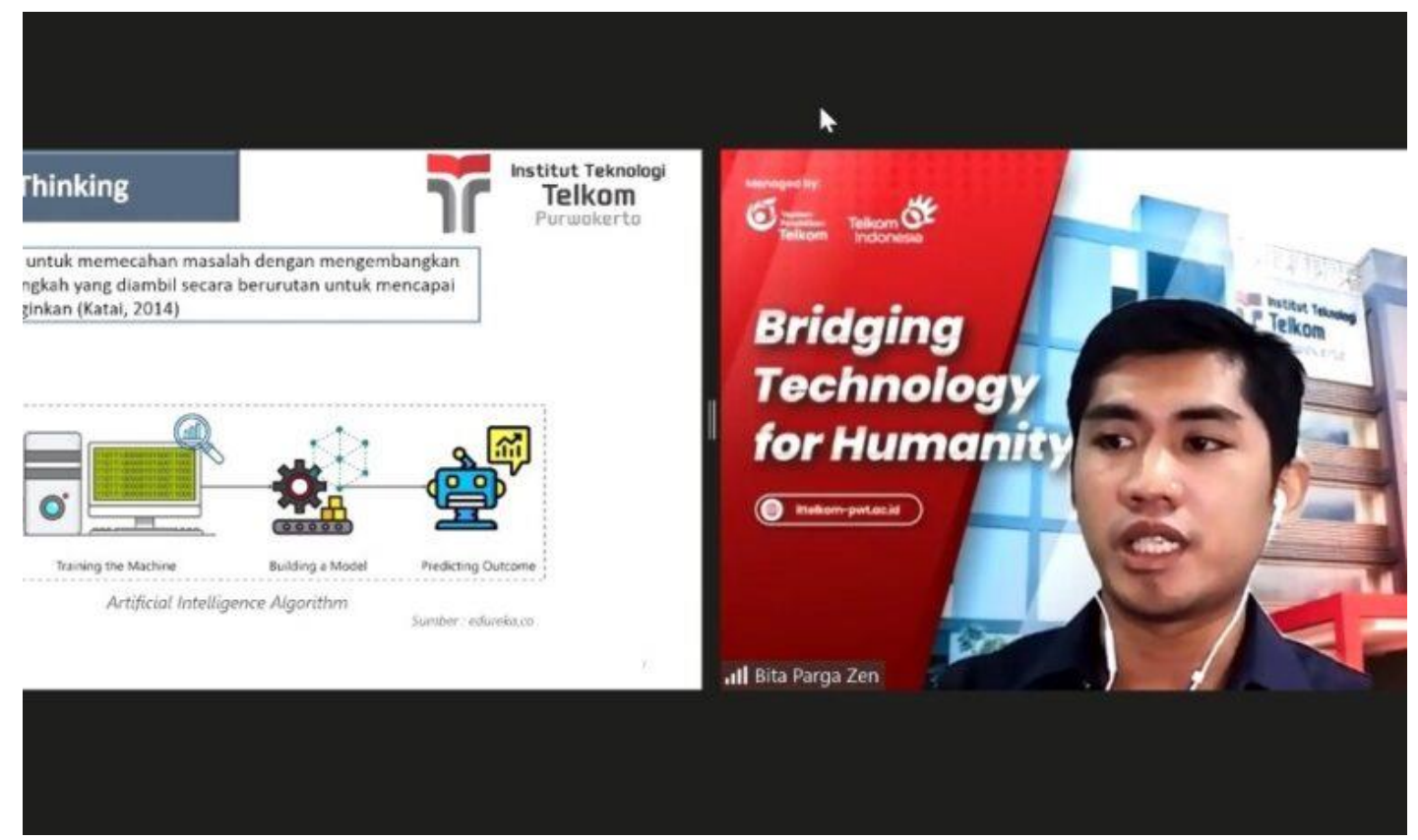

Gambar 2. Materi Computational Thinking

Keberhasilan program webinar pengabdian masyarakat mengenai kompetensi berfikir komputasi menuju era societ 5.0 dinilai berdasarkan seberapa besar penyerapan tenaga kerja saat ini dan kebutuhan teknologi informasi saat ini terhadap lulusan dari institut teknologi telkom yang diserap oleh industri. Hal ini berdasarkan data dari institusi. Adanya webinar ini memberikan gambaran akan persaingan dunia kerja kedepan melalui pentingnya berfikir algoritma yang baik, berfikir kooperatif, berfikir kreatif, berfikir kritis dan penyelesaian masalah

\section{Kesimpulan}

Hasil pengabdian kepada masyarakat menunjukkan bahwa sebagaian besar peserta webinar antusias untuk mengetahui tentang berfikir komputasi di era society 5.0 terutama untuk lulusan IT dan mahasiswa Institut Teknologi Telkom Purwokerto. Para peserta sendiri senang dengan adanya webinar ini dan ingin bisa berkelanjutan. Webinar ini memberikan gambaran akan persaingan dunia kerja kedepan melalui pentingnya berfikir algoritma yang baik, berfikir kooperatif, berfikir kreatif, berfikir kritis dan penyelesaian masalah

\section{Ucapan Terimakasih}

Terima Kasih Kepada KK TI IT Telkom Purwokerto. LPPM IT Telkom Purwokerto dan Institut Teknologi Telkom Purwokerto atas dukungan kegiatan masyarakat ini 


\section{Daftar Pustaka}

Serpa, S.; Ferreira, C. Society 5.0 and Social Development: Contributions to a Discussion. Management and Organizational Studies 2018, 5, 26-31.

Valerie J.Shute., ChenSun., Jodi Asbell Clarke (2017) Demystifying computational thinking. v22 p142158. doi.org/10.1016/j.edurev.2017.09.003

Doleck, Tenzin "Algorithmic thinking, cooperativity, creativity, critical thinking, and problem solving: exploring the relationship between computational thinking skills and academic performance" Beijing Normal University 2017

Riley, D. D. dan Hunt, K. A. (2014). Computational Thinking for the Modern Problem Solver. Florida: CRC Press.

"Society 5.0 and Social Development" doi:10.20944/preprints201811.0108.v1 Preprints.org Government.C. O. (2018). Society 5.0. Japan.

Ely Nasititi "Kesiapan Pendidikan Indonesia Menghadapi era society 5.0" Universitas Nuta Bangsa eISSN: 2599-2139

Vasconcelos, Jorge "Basic Strategy for Algorithmic Problem Solving" 2017 Science performance (PISA) (indicator). doi: 10.1787/91952204-en (Accessed on 05 March 2021)

Marcello Missiroli "Cooperative Thinking : Computational Thinking meets Agile"2017 IEEE 30th Conference on Software Engineering Education and Training (CSEE\&T)

edureka.co "artificial intelligence algorithms" akses 11 Maret 2021 